\title{
Investigating Youth Learning and Data: Contexts, Concepts, and Connections
}

\section{Amelia Acker}

University of Texas at Austin, School of Information, USA. aacker@ischool.utexas.edu

\section{Dania Bilal}

University of Tennessee, Knoxville, School of Information Sciences, USA. dania@utk.edu

\section{Leanne Bowler}

Pratt Institute, School of Information, USA.

lbowler@pratt.edu

\author{
Patricia Garcia \\ University of Michigan, School of Information, USA. \\ garciapg@umich.edu
}

Eric M. Meyers

University of British Columbia, School of Library, Archival and Information Studies, Canada. eric.meyers@ubc.ca

\author{
Yan Zhang \\ University of Texas at Austin, School of Information, \\ USA.yanz@ischool.utexas.edu
}

\begin{abstract}
This panel presents research that has explored young people in relation to data traces in digital, networked platforms supported and made accessible through Internet connected devices, applications, and platforms, asking the question: how might we help youth, as data subjects, gain a sophisticated understanding of data, including the processes involved in data creation, collection, curation, and aggregation with networked devices, platforms, and information services? Panelists will convene around the impact of these new technologies in youths' lives by presenting a range of empirical research on search engines, identity-based gaming, literacy groupware for children, and data literacy programming for youth in public libraries.
\end{abstract}

\section{KEYWORDS}

Data, youth, libraries, literacy

\section{INTRODUCTION}

The data ecosystem "brings surveillance into the intimate space of a child's life, tracking their gestation, sleep, play, talk, learning and much more" (Livingstone \& Third, 2017) and configuring children and youth "as algorithmic assemblages" for the benefit of powerful others. (Lupton \& Williamson, 2017). The effect of mass data collection on the development of young people and their digital subjectivity is as yet unknown, particularly in the areas of privacy, identity development, learning, selfefficacy, and individual freedom. Given the rapidly emerging data regimes within which today's young people grow up, the time is right to explore the unique data literacy needs of youth in terms of their critical and civic participation in a data driven society and how we might empower young people to be agents of change in relation to computational, data-driven infrastructures.

\section{BACKGROUND AND MOTIVATIONS}

Data literacy is a new construct in the fields of education and libraries, its meaning still open to negotiation. Although many have advocated for the education of a data literate population, there is little consensus on what such educational programs should look like, how it is defined, and what competencies for youth should be. Traditional approaches to data literacy emphasize quantitative reasoning by focusing on numeracy, statistics, and computer programming while a broader view interprets data literacy to be a new liberal art that includes humanistic reasoning skills. Situating data literacy in the context of personal data management gives young people a meaningful frame to apply as they work toward the development of analytic skills needed to create, collect, manage and curate data sets in their lives.

Though there is a robust literature about digital youth and information literacy skills, data literacy is under-theorized and continues to be focused on more formal learning contexts. There is little empirical research that examines teen data literacy, especially in the context of the public library. This panel brings together six "digital youth" scholars from the ASIS\&T community to discuss their research agendas in areas related to youth, data and information in digital contexts. Each panelist will present current research that explores young people in relation to data traces in digital, networked platforms supported and made accessible through Internet connected devices, applications, and platforms, asking the question: how might we help youth, as data subjects, gain a sophisticated understanding of data, including the processes involved in data creation, collection, curation, and aggregation with networked devices, platforms, and information services? Panelists will convene around the impact of 
these new technologies in youths' lives by presenting a range of empirical research on search engines, identity-based gaming, literacy groupware for children, and data literacy programming for youth in public libraries.

\section{PANEL FORMAT AND PRESENTATION ABSTRACTS}

We have assembled a panel of researchers currently conducting research in the area of youth, data, and digital networked platforms and services. Amelia Acker will begin the session with a brief introduction to the data literacy problem space (10 minutes). She will then be followed by five panelists: Dania Bilal and Yan Zhang will discuss how young people interpret the snippets listed on the search engine results page (SERP) and what that suggests about their mental model of the inner workings of search (15 minutes); Eric Meyers explores an emerging type of literacy groupware system that quantifies early literacy practice, changing the way children and adults perceive the practice of reading (15 minutes); Patricia Garcia shares her experiences developing a culturally responsive data literacy program (15 minutes) and; Leanne Bowler and Amelia Acker conclude the panel presentation with a look at their findings vis à vis education for data literacy in the context of Teen Services at the public library (15 minutes). We will then open the floor to audience questions and comments (20 minutes). In total the session will run 90 minutes.

\section{Youths' Mental Models of Search Engine Results Pages (SERPs)}

Have you ever wondered what the ranked SERPs snippets mean to the youth? In a previous study, youth indicated that the topranked snippet that a search engine retrieves is the most popular, most reputable, most useful, most trustworthy, or most familiar (Gwizdka \& Bilal, 2017). In this presentation, Bilal and Zhang will share the preliminary results of a survey-based study that explores youth's mental models of search engine SERPs, including but not limited to ranking order, structure of snippets, how snippets are generated, perceived importance in terms of providing answers to questions, and other features youth attach to SERPs snippets. Previous studies that examined people's mental models of the Web and search engines did not consider youth. The aim of this study is to explore youth's mental models of SERPs snippets to shed light on whether one-size-fits-all SERPs indeed mean the same for different user groups. These results augment our understanding of how youth conceptualize SERPs beyond what has been explored by researchers (e.g., Gossen, Höbel, \& Nürnberger, 2014; Mlilo \& Thatcher, 2011) and how such conceptualization differ from adults' mental models (e.g., Mlilo \& Thatcher, 2011; Zhang, 2008). Practically, these results inform the design of increasingly more adaptive SERPs and innovative ways for teaching web information literacy.

\section{Promoting Critical Data Literacy in Youth Tech Programs}

Scholars have argued that studying the impact of digital technologies on youth requires more than a "screen-deep" analysis and have challenged us to examine the machinic and human practices embedded within networked platforms and services (Nakamura, 2014). In this presentation, Garcia will present preliminary findings from a multi-sited qualitative study on the interplay between critical data literacy and youth identity development. The presentation will include an overview of a culturally responsive computing program designed to encourage teens to think critically about 1) the forms of data collected through everyday online experiences, and 2) how the data is used to create an "algorithmic identity" that is classed, raced, and gendered (CheneyLippold, 2011; Noble, 2018). Drawing on data from a nine-month study, Garcia will discuss findings from an activity designed to promote positive self-concepts among girls (ages 13-16) through the deconstruction of an identity-based gaming platform. The findings presented will use participant observations and artifact analysis to illustrate how teaching youth to examine data practices can facilitate discussions about the impact of algorithms on personal identity formation, the "datafication" of daily activities, and the design of socio-technical systems.

\section{Literacy as Data: The Quantified Child Reader}

This presentation will discuss the data implications of mediatized reading through an educational platform we term children's literacy groupware. We define this emerging technology as cloud-based reading management systems that combine digital reading collections with behavior tracking and analysis, communication tools, and reader incentives. Children's literacy groupware extends the notion of a digital library for children (e.g., Druin, 2005) as they provide value-added tools for teaching, monitoring, evaluating, and encouraging young readers. The systems enable adult stakeholders (e.g., teachers, parents, caregivers) to track and manage the reading activities of one to dozens of children. Meyers will report on his research team's inquiry into two for-profit app-based systems that provide reading content and instruction for elementary age children in North America and throughout the world. This investigation is part of a larger conceptual and empirical study of the use of networked, digital information systems that document the daily activities of children. We argue that these systems are shifting children's practices in school and home environments, including reading, play, exploration, and socialization (Meyers, Nathan \& Stepaniuk, 2017). Our overarching research question is: How do systems for managing engagement with digital texts frame (or reframe) reading practice--the what, where, when and how of reading, including behaviors, attitudes and dispositions toward reading? Literacy groupware generates a wealth of data about reading behavior that has the potential to radically change the way we teach and assess beginning readers. However, Meyers will also point out the pitfalls of "quantifying" the reading experience through 
dashboards and reading metrics, which may isolate and objectify the reader, decontextualizing reading practice through a "one size fits most" approach and shift the locus and perceived responsibility of reading instruction. Most importantly, we will outline the tensions among stakeholder uses and data awareness, such as the contradiction between reading as pleasure and reading as labour. The presentation will include several suggestions, generated through our content analysis and interviews with multiple stakeholders (children, parents, teachers), that will help develop future iterations of these systems, as well as propose alternative deployment strategies to help reconfigure networked reading practice.

\section{Entry Points into Data at the Public Library}

The public library needs data literacy models that address the everyday concerns of youth, particularly with respect to their digital traces, and which align with the humanistic, community-oriented goals, and unique pedagogy of this public institution. In much of the literature, data literacy is presented as a set of skills related to numeracy, statistics and computation (See for example, Gunther, 2007; van't Hooft et al, 2013; Fontichiaro \& Oehrli, 2016). In terms of library-based approaches to data literacy, we must look to the world of academic libraries, where models of data literacy focus on the management and use of data as a product of scholarly research (Prado \& Marzal, 2013; Carlson \& Johnston, 2015, Shorish, 2015), and to the school library environment, which explores data skills primarily through the lens of statistics and visualization (Fontichiaro et al, 2017, Abilock et al, 2017). There is, however, a dearth of empirical models that situate data fluency within the context of Teen Services at the public library, even though programming that provides learning experiences with data is already occurring through digital media labs, makerspaces, and youth hackathons (Dankoski, 2018). We present here, as part of the Exploring Data Worlds at the Public Library project, a preliminary framework for supporting the development of data literacy at the public library - a method for opening a gateway toward data programs that are both meaningful and engaging to young people and at the same time, doable in the library context. It builds upon the authors' earlier work exploring data through the eyes of young people - what it is and how it configures in their everyday lives (Acker \& Bowler, 2017; Bowler et al, 2017).

\section{PANELISTS' BIOGRAPHIES}

Dr. Amelia Acker is Assistant Professor of Information in the School of Information at the University of Texas at Austin. She holds a PhD and MLIS from University of California, Los Angeles where she was also an archivist. Dr. Acker studies the emergence and standardization of new information objects and data traces communication networks. Currently, she is researching data cultures, information infrastructures and digital preservation contexts that support long term cultural memory. Her current research program addresses emerging digital traces and mobile computing cultures that are shaped by new data collection practices amongst different kinds of users, designers, technologists, and institutions.

Dr. Dania Bilal is a Professor at the School of Information Sciences, the University of Tennessee, Knoxville. She obtained her $\mathrm{PhD}$ in Library and Information Studies from the Florida State University School of Library and Information Studies in 1988. Since her appointment to the faculty in August 1997, she has taught courses in human-computer interaction, web mining, research methods, information systems design and implementation, and information access and retrieval, among others. Her research is at the intersection of information behavior, information retrieval, and human-computer interaction with a focus on children. She has published work on children's use of web search engines, interaction with international digital libraries, conceptual structures, design of search engine interfaces, and compared their web information behaviors with the behaviors of adults.

Dr. Leanne Bowler is an Associate Professor at the Pratt Institute's School of Information in New York City. She received her $\mathrm{PhD}$ from McGill University and holds Master's degrees in Education as well as Library Science. Her research focuses on youth technology practices and how family, teachers, and out-of-school organizations like libraries support young people's competencies in socio-technical environments. She has expertise in the study and practice of participatory design with young people, which directly involves youth in the development of services and technologies that sup- port positive interactions with information and data. Additionally, Dr. Bowler researches how to support STEM learning in public libraries, most recently through a project exploring youth data literacy programs in library-based technology centers.

Dr. Patricia Garcia is an Assistant Professor at the University of Michigan, School of Information. She conducts sociocultural research on race, gender, and technology with a special interest in studying how the use of culturally responsive computing practices can increase girls' participation in STEM activities. She conducts interdisciplinary action research on race, gender and technology with a special interest in studying the role of information institutions in promoting equitable and culturally responsive STEM programming for girls of color. Her current work focuses on broadening participation in computer science by developing a low-resource model for teaching computational thinking skills in informal learning environments, such as libraries. She holds a $\mathrm{PhD}$ in information studies from the iSchool at UCLA.

Dr. Eric M. Meyers is an Associate Professor at the School of Library, Archival and Information Studies (SLAIS) at the University of British Columbia, where he teaches and conducts research on the information practices of young people in academic 
and everyday contexts. Dr. Meyers' research interests lie at the intersection of information science, the learning sciences, and new media studies, with a focus on collaborative information use and meaning making in social situations.

Dr. Yan Zhang is an associate professor in the School of Information at the University of Texas at Austin. She holds a Ph.D. in Information and Library Science from the University of North Carolina at Chapel Hill. Her research focuses on general consumers' information seeking behavior, particularly online health information search behavior using both search engines and social media, as well as users' mental models of search engines and information-rich web spaces.

\section{REFERENCES}

Abilock, D., Ballard, S.D., Bergson-Michelson, T., Colby, J., Fontichiaro, K., Hoelter, L., Joque, J., Oehrli, J.A., Seroff, J., Smith, S. and Steelberg, T. (Eds.). (2017). Creating Data Literate Students. Michigan Publishing, University of Michigan Library.

Acker, A. \& Bowler, L. (2017). Youth data literacy: Teen perspectives on data created with social media and mobile device ownership. Hawaii International Conference on System Sciences 2018 (HICCS). January 3-6, 2018.

Bowler, L., Acker, A., Jeng, W. \& Chi. Y. (2017). “It lives all around us”: Aspects of data literacy in teens' Lives. 80th ASIS\&T Annual Meeting. Diversity of Engagement: Connecting People and Information in the Physical and Virtual Worlds. October 27-November 1, 2017. Washington, D.C.

Carlson, J. \& Johnston, L.R. (Eds). (2015). Data Information Literacy: Librarians, Data, and the Education of a New Generation of Researchers. (Purdue Information Literacy Handbooks). Ashland, OH: Purdue University Press.

Cheney-Lippold, J. (2011). A new algorithmic identity: Soft biopolitics and the modulation of control. Theory, Culture \& Society, 28(6), 164-181.

Dankowski, T. (2018). Engaging civic-minded teens: Data literacy fosters YA participation and innovation. American Libraries. March/April, pp. 38-41.

Druin, A. (2005). What children can teach us: Developing digital libraries for children with children. The Library Quarterly, 75 (1), $20-41$.

Fontichiaro, K., Lennex, A., Hoff, T., Hovinga, K. \& Oehrli, J.A. (Eds.). (2017). Data Literacy in the Real World: Conversations \& Case Studies. Maize Books Michigan Publishing.

Fontichiaro, K. \& Oehrli, J.A. (2016). Why data literacy matters. Knowledge Quest, 44(5) (May/June), 20-27.

Gossen, T., Höbel, J., \& Nürnberger, A. (2014). A comparative study about children's and adults' perception of targeted Web search engines. Proceedings of the SIGCHI Conference on Human Factors in Computing Systems (pp. 1821-1824). New York, NY, USA: ACM. https://doi.org/10.1145/2556288.2557031

Gunter, G.A. (2007). Building student data literacy: An essential critical-thinking skill for the 21st century. Multimedia \& Internet @ Schools, 14(3), 24-28.

Gwizdka, J., \& Bilal, D. (2017). Analysis of children's queries and click behavior on ranked results and their thought processes in Google search. Proceeding of CHIIR"'17 of the 2017 Conference on Human Information Interaction and Retrieval (pp.377-380). Oslo, Norway, March 7-11. Doi: >10.1145/3020165.3022157.

Livingstone, S., \& Third, A. (2017). Children and young people's rights in the digital age: An emerging agenda. (2017): 657-670.

Lupton, D., \& Williamson, B. (2017). The datafied child: The dataveillance of children and implications for their rights. New Media \& Society, 19(5), 780-794.

Meyers, E. M., Nathan, L. P., and Stepaniuk, C. (2017). Children in the cloud: Literacy groupware and the practice of reading. First Monday, 22 (2). http://firstmonday.org/article/view/6844/5845. doi: http://dx.doi.org/10.5210/fm.v22i2.6844

Mlilo, S. \& Thatcher, A. (2011). Mental Models: Have users' mental models of Web search engines improved in the last ten years? International Conference on Engineering Psychology and Cognitive Ergonomics EPCE 2011 (pp. 243-253). Orlando, FL, USA, July 914.

Nakamura, L. (2014). Indigenous circuits: Navajo women and the racialization of early electronic manufacture. American Quarterly, 66(4), 919-941.

Noble, S. U. (2018). Algorithms of Oppression: How Search Engines Reinforce Racism. NYU Press.

Prado, J.C. \& Marzal, M.A. (2013). Incorporating Data Literacy into Information Literacy Competencies and Contents. Libri, 63 (2), 123 135.

Shorish, Y. (2015). Data information literacy and undergraduates: A critical competency. College and Undergraduate Libraries, 22(1), 97106.

Van't Hooft, M., Vahey, P., Swan, K. Kratcoski, D. C. \& Rafanan, K. (2012). A cross-curricular approach to the development of data literacy in the middle grades: The Thinking with Data project. Middle Grades Research Journal, 7(3) 19-33.

Zhang, Y. (2008). Undergraduate students' mental models of the Web as an information retrieval system. Journal of the American Society for Information Science and Technology, 59(13), 2087-2098.

$81^{\text {st }}$ Annual Meeting of the Association for Information Science \& Technology | Vancouver, Canada | 10 - 14 November 2018 Author(s) Retain Copyright 